'excitation-contraction coupling' in muscles to which we have already directed attention ${ }^{2-4}$.

W. W. Douglas

R. P. RUBIN

Department of Pharmacology,

Albert Einstein College of Medicine, New York 61.

${ }^{1}$ Hermann, H., Bull. Acad. Med., Paris, 126, 234 (1942).

'Douglas, W. W., and Rubin, R. P., J. Physiol., 159, 40 (1961).

'Douglas, W. W., and Rubin, R. P., J. Physiol., 167, 288 (1963).

- Douglas, W. W., and Poisner, A. M., J. Physiol., 162, 385 (1962).

${ }^{6}$ von Euler, U. S., and Floding, I., Scand. J. Clin. Lab. Invest., 8, 288 (1956).

'Anton, A. H., and Sayre, D. F., J. Pharmacol., 138, 360 (1962).

"Mullins, L. J., Ann. N.Y. Acad. Sci., 94, 390 (1961).

- Douglas, W. W., and Poisner, A. M., Nature, 192, 1299 (1961).

- Douglas, W. W., Second Intern. Pharmacol. Meeting, Prague, 1963 (Pergamon Press; in the press).

10 Daniel, E. E., Arch. Int. Pharmacodyn., 146, 298 (1963).

\section{Anomalous Reactions of the Rat to Ganglion Blocking Agents}

IN work which will be reported elsewhere it was found that certain extracts of the solanaceous plant Cestrum parqui caused a pronounced and prolonged elevation of the blood pressure of the anæsthetized rat. Since this reaction did not occur in the pithed animal, attempts were made to block the pressor effect at the autonomic ganglia. When hexamethonium failed to block the effects of C. parqui extracts it was decided to examine the effects of ganglion blocking agents per se in the rat.

Male albino rats of an inbred line originating from the Wistar strain and weighing 210-245 g were anæsthetized by intraperitoneal injection of urethane or intravenous injection of pentobarbitone sodium. Blood pressure was recorded from the left common carotid artery. The right common carotid artery was cleared and made available for clamping at intervals for 30 -sec periods. Intravenous injections were made into the tail veins and washed in with 0.9 per cent saline. The doses which follow refer to amounts of base in each case, the substances used being hexamethonium (as the bromide, iodide or tartrate), pempidine tartrate, mecamylamine hydrochloride and 1-noradrenaline base.

Initially, hexamethonium was injected intramuscularly in a dose of $10 \mathrm{mg} / \mathrm{kg}$, this being the dose used by $\mathrm{Kärki}^{1}$ to stabilize the blood pressure and sensitize the animal to catecholamines. This produced a slight fall in blood pressure, but was without effect on the rise resulting from clamping of the right carotid artery. In subsequent experiments, intravenous hexamethonium in doses ranging from 1 to $10 \mathrm{mg} / \mathrm{kg}$ caused a marked blood-pressure fall, but whether or not an additional 5 or $10 \mathrm{mg} / \mathrm{kg}$ has been given intramuscularly or subcutaneously, there was never complete suppression of the pressor response to carotid clamping. This response, although markedly diminished during the first minute or two after intravenous injection, rapidly returned to its previous level. Subsequent repetitive dosage with hexamethonium intravenously had less and less blocking effect on the response, and after 3 or 4 doses of $10 \mathrm{mg} / \mathrm{kg}$ the response was markedly enhanced. This pattern continued with further doses, the animals usually dying after a total of 70-80 $\mathrm{mg} / \mathrm{kg}$ had been administered over a period of $\mathrm{I} \cdot 5-2 \mathrm{~h}$.

Similarly, pempidine intravenously in doses ranging from $0.1 \mathrm{mg} / \mathrm{kg}$ to $5 \mathrm{mg} / \mathrm{kg}$, and mecamylamine intravenously in doses of $0.5-5 \mathrm{mg} / \mathrm{kg}$ never completely blocked the pressor response to carotid clamping. With each drug, repetitive dosago at tho $5-\mathrm{mg} / \mathrm{kg}$ level eventually enhanced the response.

The sensitizing effect of doses of hexamethonium 'too small to influence ganglionic transmission' in the rat submitted to carotid occlusion and noradrenaline injections has been reported by Sultan Mawji and Lockett ${ }^{2}$. The very large doses used in the present experiments, as well as enhancing the carotid reflex, also enhanced the response to injected noradrenaline. Furthermore, hexamethonium itself in some circumstances produced a marked pressor response. This was observed in the pithed rat preparation, after several doses of noradrenaline and three or four successive doses of hexamethonium $10 \mathrm{mg} / \mathrm{kg}$. Afterwards, similar injections of hexamethonium caused a blood-pressure rise comparable in height and duration with the effect of $50 \mathrm{ng}$ of noradrenaline. Injection of saline controls eliminated the possibility of the pressor effect being due to venous stagnation of earlier doses of noradrenaline.

It is of interest to note that examples of quaternary, tertiary and secondary amine ganglion blocking drugs were unable to block the pressor response to carotid occlusion in the rat, and that in fact all three agents in high dosage enhanced the response. Of the procedures used, only pithing the animals completely obliterated the pressor response.

\section{J. M. WHYTE}

Department of Physiology,

University of Queensland, Brisbane.

${ }^{1}$ Kärki, N. T., Acta physiol. scand., 39, Supp. 132, 28 (1957).

${ }^{2}$ Sultan Mawji and Lockett, M. F., J. Pharm. Pharmacol., 15, 45 (1963).

\section{PATHOLOGY}

\section{Resistance against Carcinomas of the Skin induced by Dimethylbenzanthracene (DMBA) in Mice of the Strain XVII/BIn}

PAST investigations in many laboratories concerning the antigenicity of experimental tumours have revealed that almost all the sarcomas induced by carcinogenic hydrocarbons contain specific antigens. For this reason a certain pretreatment of isologous recipients with these tumours can produce resistance against cell inocula of the tumour originally taken for immunization. Using this test system specific antigens were demonstrated in sarcomas which were induced by administration of methylcholanthren $\Theta^{1-7}$, benzpyren $\Theta^{5,8,9}$, dibenzpyrene $\theta^{6}$, dibenzanthracene ${ }^{10}$, and dimethylbenzanthracene ${ }^{11}$.

Dependent on the mode of application the same substances are capable of producing carcinomas. Those tumours develop if the carcinogen acts on tissue of epithelial origin.

The demonstration of host resistance against grafts of the irduced carcinomas would mean that the development of specific antigens is not only a characteristic of the sarcomas, that is, of tumours of mesodermal tissue origin, but also of tumours which arise from epithelial tissue under influence of the carcinogen.

First evidence for a tumour-specific immunizing capacity of epithelial tumours was obtained by Prehn ${ }^{12}$, who has shown that methylcholanthrene-induced breast tumours (adenoacanthomas) of the $B A L B / c A n$ strain were antigenic in isologous hosts.

In this communication experiments on the induction of resistance against isologous cell inocula of DMBA-induced carcinomas of the skin are described.

Experimental animals were female mice of the strain XVII/Bln. For the purpose of tumour induction an acetone solution containing 0.01 per cent DMBA was prepared. Twice a week for a period of 10 weeks one group of mice (about 3 months old) was treated with the carcinogen-containing solution. Using a glass capillary to each mouse 3 drops of the solution were given to the dorsal region of the skin. The animals received a total amount of $120 \gamma$ DMBA per mouse. The two tumours tested developed after latencies of 202 (DMBA 592) and of 267 (DMBA 788) days. Histologically they have been identified as keratinizing squamous epithelium carcin- 